\title{
Psychobiotic Therapy: Method to Reinforce the Immune System
}

\author{
Karina Teixeira Magalhães-Guedes \\ Department of Bromatological Analysis, Pharmacy Faculty, Post-Graduate Program in Food Science, Federal University of Bahia (UFBA), Salvador, \\ Brazil
}

Psychobiotics are probiotic microorganisms that beneficially affect the central nervous system functions mediated by the gut-brain axis, improving the host's immune system. Psychobiotic microorganisms can regulate brain pathways and serotonin production (mood controller). The main microbial genera with psychobiotic characteristics are Lactobacillus, Lactococcus and Bifidobacterium. The daily consumption of psychobiotics is called "Psychobiotic Therapy". Psychobiotic therapy has proven antidepressant/anxiolytic properties. Psychobiotic therapy can be used to boost the host's immune balance against pathogens, for example: virus, bacteria and fungus. Thus, psychobiotic therapy can be a promising strategy to improve and/or maintain the quality of life of people who are healthy or who suffer from anxiety/stress disorders, intestinal dysbiosis and even immunosuppressed people. This is such a hot theme it can surely only be a matter of time for psychobiotic therapy offers an "alternative treatment", but scientific, for people diagnosed with a variety of mental/immunological disorders. Instead of targeting the mind (brain), we could go for the gut. "This new way of looking at mental health linked to gut health is literally looking at health upside down”.

KEY WORDS: Healthy food therapy; Healthy immune system; Psychobiotics in food; Method to reinforce the health; Psychobiotics against anxiety/stress.

\section{INTRODUCTION}

In the present paradigm, where the a properly functioning immune system is important and integral for counteracting pathogen infection [1], shows us the importance of balancing the immune system and studying the relationship of the immune response with the gut-brain axis through the use of probiotic microorganisms [2-4]. Gutbrain axis is a complex system that helps the body. This axis involves the functions of the gut with the brain providing good health to the host $[3,5]$.

External factors such as the use of antibiotics, poor diet and pathogens affect the host health $[5,6]$. Based on this information, is important the use of psychobiotics to reinforce the host immune balance against pathogens $[7,8]$.

Received: February 25, 2021 / Revised: June 15, 2021

Accepted: July 21, 2021

Address for correspondence: Karina Teixeira Magalhães-Guedes Department of Bromatological Analysis, Pharmacy Faculty, Post-Graduate Program in Food Science, Federal University of Bahia (UFBA), Barão of Geremoabo Street, s/n, Ondina, Salvador, Bahia 40171-970, Brazil

E-mail: karynamagat@gmail.com

ORCID: https://orcid.org/0000-0001-5775-9331
Psychobiotics are probiotics microorganisms strains that have potential application in the treatment mental and physical host health [2-4].

In previous studies, various psychobiotics strains were in vivo studied to improve the host mental health [4,7-9]. When psychobiotics are used orally in daily food, they are called "Psychobiotic Therapy" $[4,9,10]$, that is, the daily intake of probiotic microorganisms and probiotic foods can generate a healthy balance in the host body $[4,9,10]$. The use of psychobiotics as therapy, with emphasis on their properties to reinforce the immune system, are discussed here.

\section{METHODOLOGY}

A bibliographic research study was conducted to collect data and information on "psychobiotics to reinforce the immune system". The research sites accessed were: e-books, theses and the Scielo database, Google Scholar, Medline, Pubmed, Science Direct and CAPES periodical portal and the virtual health/food library. The index terms used for searches were psychobiotics, probiotics, pro-

(c) This is an Open-Access article distributed under the terms of the Creative Commons Attribution Non-Commercial License (http://creativecommons.org/licenses/by-nc/4.0) which permits unrestricted non-commercial use, distribution, and reproduction in any medium, provided the original work is properly cited. 
biotics microrganisms on immune response, psychobiotic therapy, microbiome-gut-brain axis, body's health and mental health. Papers that did not match the searched words were excluded. The exclusion criterion also applied to articles that after reading that did not refer to the main objective of the study. As scientific research on "Psychobiotics" is recent, years of publication were not exclusion criteria. In total, 60 scientific articles were recruited.

\section{RESULTS}

\section{Psychobiotics}

Psychobiotics are probiotics microorganisms strains that have potential application in the treatment mental and physical host health [2-4]. Psychobiotic microorganisms can regulate brain pathways and serotonin production (mood controller) [11]. Serotonin (5-hydroxytryptamine) is principally found stored in three main cell types: i) serotonergic neurons in the central nervous system and in the intestinal myenteric plexus, ii) enterochromaffin cells in the mucosa of the gastrointestinal tract, and iii) in blood platelets. Serotonergic neurons and enterochromaffin cells can synthesize serotonin from it precursor amino acid L-tryptophan, whereas platelets rely upon uptake of serotonin for their stores. Likewise, serotonergic neurons also have the capacity for amine uptake via serotonin transporters. Serotonin is also synthesized in the pineal gland as a precursor for the subsequent enzymatic formation of the pineal hormone melatonin ( $\mathrm{N}$-acetyl-5-methoxytryptamine). The biochemical pathway for serotonin synthesis initially involves the conversion of L-tryptophan to 5-hydroxytryptophan by the enzyme L-tryptophan hydroxylase (TPH), which has been found both in cytosolic and particulate brain cell fractions. This enzyme provides the rate-limiting step for serotonin synthesis, in the same manner that norepinephrine and dopamine synthesis in adrenergic and dopaminergic neurons is controlled by the ability of the related enzyme, L-tyrosine hydroxylase, to convert L-tyrosine to L-dihydroxyphenylalanine (L-DOPA). Some inhibitors of TPH (e.g., $\alpha$-propyldopacetamide) are also active against tyrosine hydroxylase, whereas others such as p-chlorophenylalanine are more selective for TPH. Although p-chloroamphetamine and fenfluramine can also inhibit $\mathrm{TPH}$, they have important actions (including neurotoxic effects) upon various other regulatory processes of seroto- nergic neuronal function. The identification of two enzyme isoforms, called TPH1 and TPH2, which are apparently associated selectively with peripheral tissues and the brain, respectively, suggests the possibility that drug inhibitors with specificity for targeting individual isoforms may be found in the future. The subsequent metabolic step in the synthesis of serotonin (and also norepinephrine or dopamine) involves the decarboxylation of 5-hydroxytryptophan (and L-DOPA) by the action of the cytosolic enzyme L-aromatic amino acid decarboxylase. Metabolism of serotonin is carried out primarily by the outer mitochondrial membrane enzyme monoamine oxidase (MAO), which occurs as two molecular subtypes called MAO-A and MAO-B. Both subtypes have a widespread occurrence in the brain and in peripheral tissues. Regular use of psychobiotic microorganisms has a direct role in the host immune balance $[9,11,12]$.

Stress, even at a low level, induces excessive corticosterone and adrenocorticotropic release and deregulates the adrenal axis functions $[12,13]$. In addition, pro-inflammatory cytokines decrease the serotonin level, which leads to psychological disorders, such as anxiety/depression and consequent decrease in the host immunity $[12,14,15]$. Various lactic acid bacteria strains play an important role in the serotonin synthesis (described above) in the body [7] and has a direct relationship in the communication of the brain-gut axis biderectional system. Serotonin functions as a key neurotransmitter at both terminals of this system (gut and brain). Scientific evidence points to a important role for the gut microbiome in regulating of this system. The mechanism may be related to the ability of the gut microbiota to produce tryptophan assisting in serotonin synthesis (described above) in the host body [7] Main genera of psychobiotic microorganisms are in Figure $1[7,9,11,12]$. Therefore, regular consumption of probiotic strains is important for body balance, particularly to keep your immune system healthy $[7,8,12]$.

The substances consumed (prebiotics, bioactive substances, vitamins and amino acids) can be fermented by psychobiotic microorganisms present in the gut microbiome, improving the functioning of the host body [16] Prebiotics are "ingredients not metabolized by the host and fermented by the gut microbiota that have specific activities in maintaining the healthy intestine microbiota, which confer well-being and health of the host" [17]. In 2018 Betiku and collaborators reformulated the concept 


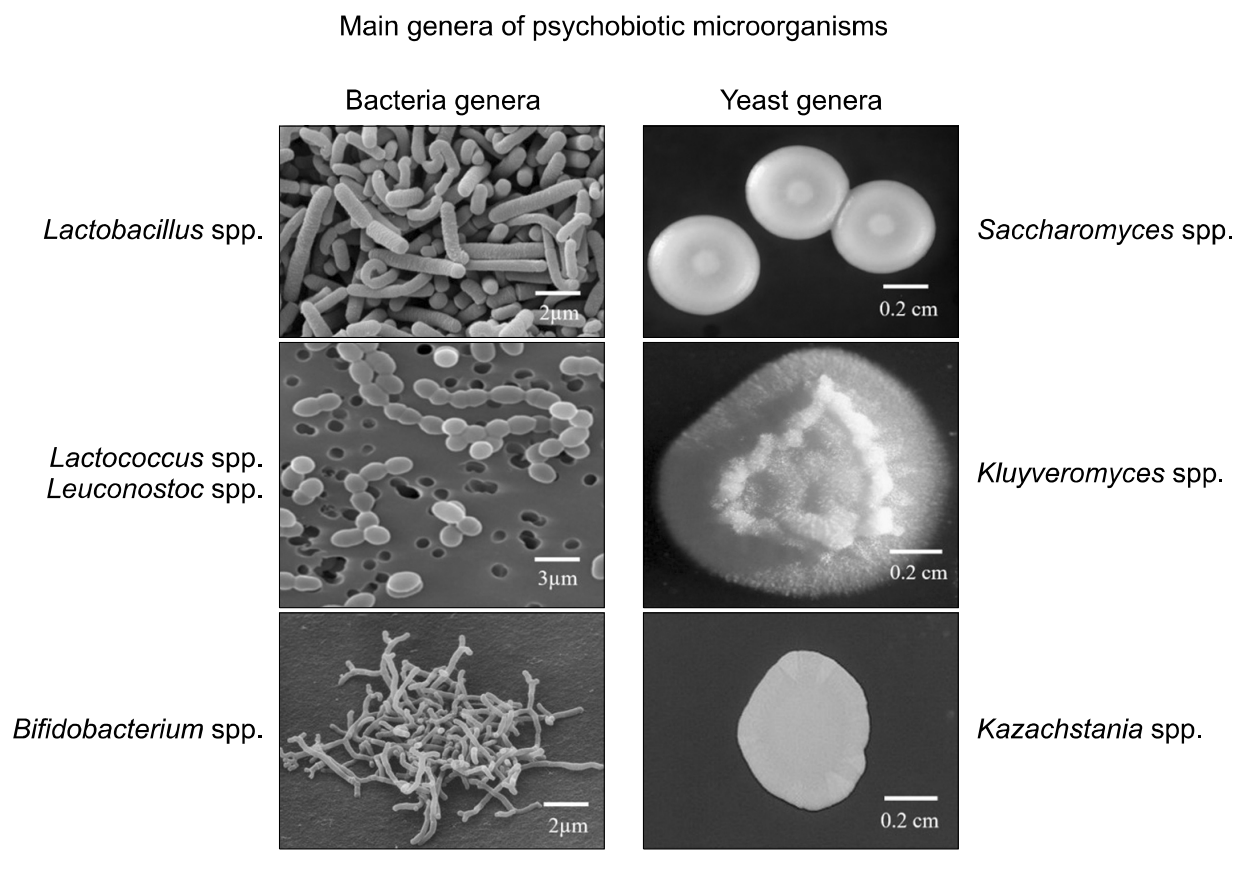

Main genera of psychobiotic microorganisms

Brain

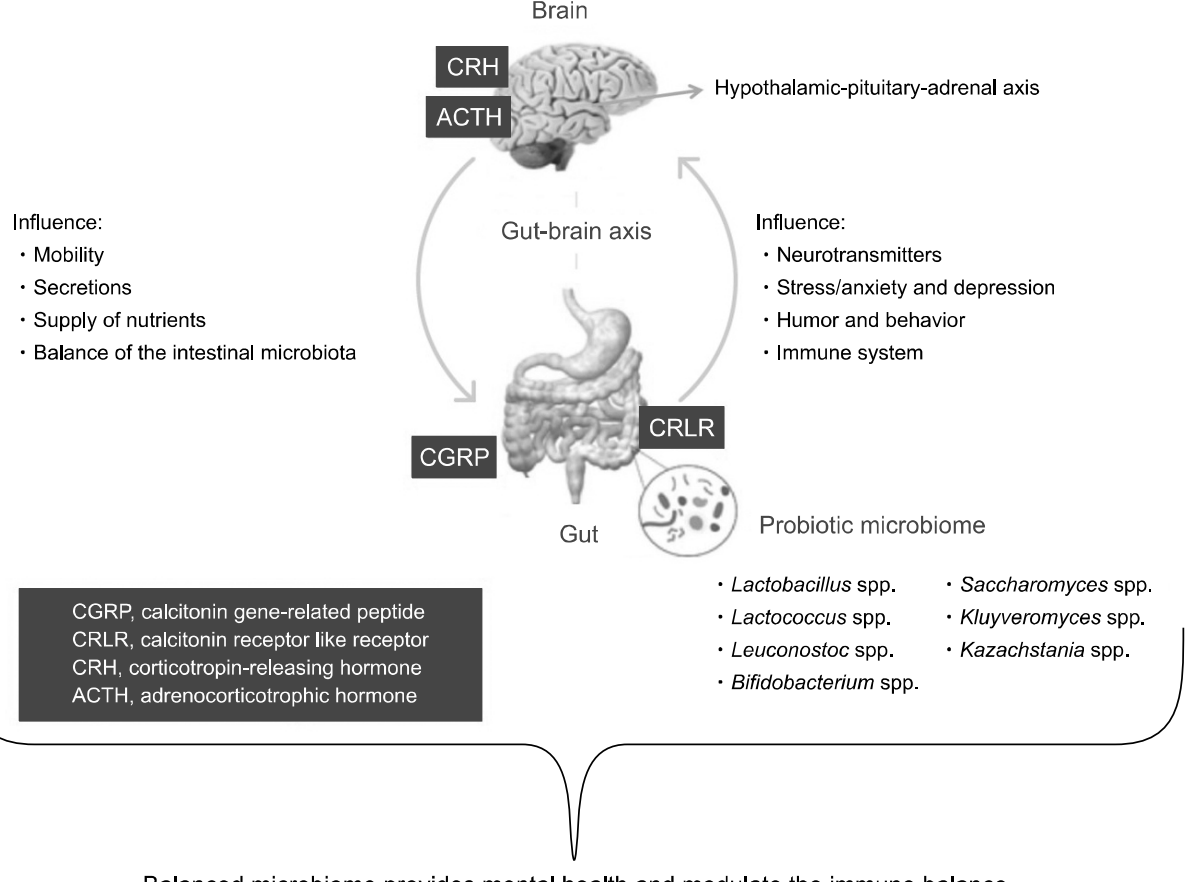

Balanced microbiome provides mental health and modulate the immune balance
Fig. 1. Main genera of psychobiotic/ probiotic microorganisms.
Fig. 2. Functional system of the "Gut-Brain Axis". of prebiotics to: "Prebiotics, which are feed ingredients that are not endogenously digestible by the host but selectively stimulate the growth of beneficial microbes in the host" [18]. These substances are converted in the gut to other active molecules, including tryptophan and serotonin and these metabolites affect the immune system and/or host central nervous system $[16,17]$.

\section{Gut-Brain Axis}

According to previous studies, the connection between gut balance and menthal/functional well-being receive the name "Gut-Brain Axis", which is is a complex system 
that helps the body, decreasing stress \anxiety levels $[3-6,19,20]$ in addition to improving the host's immune system $[6,10]$. This axis involves the functions of the gut with the brain providing good health to the host [3-6,19,20].

The gut and brain send and receive information through the neural pathways as well as through the blood system $[3-6,19,20]$. The gut-brain axis also influences the endocrine functions and nervous system, as well as the of host behavior $[3-6,19,20]$. The gut-brain axis is regulated by the activity levels of the neural, hormonal and immune systems $[6,10]$. The functional regulation of the gut-brain axis is decreased with specific changes in the stress $\backslash a n x i-$ ety levels $[3-6,19,20]$.

The functional system of the "Gut-Brain Axis" is represented by Figure 2. Calcitonin gene-related peptide (CGRP) is a substance derived from calcitonin peptides. CGRP is produced by neurons and released in the intestine when the gut microbiota is impaired with an increase in pathogenic microorganisms [6]. After the infection is activated and the CGRP secreted, the host defense and immune response are activated by the receptor like receptor calcitonin (CRLR). When the gut microbiota is balanced by probiotic microorganisms consumption, the CGRP has a regulatory effect on gut-brain axis [6]. Corticotropin-releasing hormone (CRH) and adrenocorticotrophic hormone (ACTH) are released on hypothalamicpituitary-adrenal axis and respond to the inflammation caused, in addition to activating the immune system against pathogens (Bacteria, Fungi, and Viruses) [6].

The hypothalamic-pituitary-adrenal axis is studied in humans and animals. Current studies examined the $\mathrm{CRH}$ administration in humans reproduced a neurological stress. CRH increased the gut permeability and the ACTH volume in plasma [21]. In mice studies infected with pathogenic microorganisms evaluated the action of the hypothalamic-pituitary-adrenal axis regarding the activity of $\mathrm{CRH}$ and $\mathrm{ACTH}$. The mice showed anxiety and stress disorders, proving that the gut microbiota imbalance interferes with the balance of the hypothalamicpituitary-adrenal axis [22].

The hypothalamic-pituitary-adrenal axis (HPA axis or HTPA axis) is a complex set of direct influences and feedback interactions among three components: the hypothalamus, the pituitary gland (a pea-shaped structure located below the thalamus), and the adrenal (also called "suprarenal") glands (small, conical organs on top of the kidneys). These organs and their interactions constitute the HPA axis, a major neuroendocrine system that controls reactions to stress and regulates many body processes, including digestion, the immune system, mood/ emotions, sexuality, and energy storage and expenditure. It is the common mechanism for interactions among glands, hormones, and parts of the midbrain that mediate the gut-brain axis [22]. The gut-brain axis provides a host body communication that can cause several pathological consequences if there is funcional deregulation $[2-4,23]$.

\section{Probiotics on Immune Response}

To display a beneficial impact on the host health, the probiotic microorganisms should be able to survive in stressful/harsh conditions of the stomach and gastrointestinal tract of the host. One of the ways probiotics microorganisms promote host health is by inhibiting the growth of pathogenic strains. Probiotic microorganisms compete for nutrients for growth and proliferation in the host gut, eliminating pathogens $[4,24]$. In addition, probiotic microorganisms can influence the activity of host immune cells, regulating inflammation, barrier function, and cell-to-cell signaling [24]. One way to foster healthy gut microbiota is to eat more natural and nutritious food, in addition to the consumption of probiotic microorganisms. Increasing the intake of plant fibers, vegetables, fruits, legumes, whole grains, nuts, and seeds is like provide good nutrition for the probiotic microbiota of the gut $[16,24]$. Another way to nurture a healthy gut is to consume foods that contain beneficial microorganisms (probiotics) and prebiotics. This includes the symbiotic foods, such as yogurt $[25 ; 26]$, kefir $[27,28]$ and kombucha $[29,30]$.

Studies on the probiotics microorganisms action on the host immune system have been carried out for some time. Non-recent and recent bibliographies, most reporting studies with lactic acid bacteria have shown that probiotics have an immunostimulating effect in animals and in man, although the mechanisms by which this occurs are not yet fully understood $[4,24]$.

The immunostimulating effect may be related to the probiotic microorganisms ability in interact with Peyer plaques and intestinal epithelial cells, stimulating IgAproducing $B$ cells and migration of $\mathrm{T}$ cells from the gut $[24,31]$. Regular use of probiotics increase the macro- 
phages phagocytic activity, stimulating the immune system [24]. To fight infections, the immune system must be able to identify pathogens organisms. These organisms have antigens molecules on their surface. When a pathogen gets into the body, the immune system reacts in two ways: a) The innate immune response is a rapid reaction. Innate immune cells recognize the antigens found on pathogens. These cells also react to signaling molecules released by the body in response to infection. Innate immune cells quickly begin fighting an infection. This re- sponse results in inflammation. The cells involved in this reaction can kill pathogens and/or can also help activate cells involved in adaptive immunity. b) The adaptive immune response is slower than the innate response but is better able to target specific pathogens. There are 2 main cell types involved in this response: T cells and B cells. Some T cells kill pathogens and infected cells. Other T cells help control the adaptive immune response. The main function of B cells is to make antibodies against specific antigens. Antibodies, also known as immunoglobulins,

Table 1. Characteristics of trials on the psychobiotic/probiotic microorganisms dosage effect on host body functionality

\begin{tabular}{|c|c|c|c|c|}
\hline Reference & Number of patient & Microbial intervention and dosage & $\begin{array}{l}\text { Period of } \\
\text { therapy }\end{array}$ & Results on body functionality \\
\hline Majeed et al. [43] & $\begin{array}{l}40 \text { (equal number } \\
\text { for control group) }\end{array}$ & Bacillus coagulans $\left(2 \times 10^{9} \mathrm{CFU} / \mathrm{ml}\right)$ & 3 months & $\begin{array}{l}\text { Significant improvement in } \\
\text { HAM-D and MADRS, to the } \\
\text { control group }\end{array}$ \\
\hline Kazemi et al. [39] & $\begin{array}{l}110 \text { (equal number } \\
\text { for control group) }\end{array}$ & $\begin{array}{l}\text { Lactobacillus helveticus and Bifidobacterium } \\
\text { longum }\left(10^{9} \mathrm{CFU} / \mathrm{ml} \text { each }\right)\end{array}$ & 2 months & $\begin{array}{l}\text { Significant reduction in BDI by } \\
\text { probiotic compared to the } \\
\text { control group }\end{array}$ \\
\hline Ghorbani et al. [38] & $\begin{array}{l}40 \text { (equal number } \\
\text { for control group) }\end{array}$ & $\begin{array}{l}3 \text { g POS containing Lactobacillus casei }\left(3 \times 10^{8}\right. \\
\text { CFU/g), Lactobacillus acidophilus }\left(2 \times 10^{8}\right. \\
\text { CFU/g), Lactobacillus bulgaricus }\left(3 \times 10^{9}\right. \\
\text { CFU/g), Lactobacillus rhamnosus }\left(3 \times 10^{9}\right. \\
\text { CFU/g), Bifidobacterium brevis }\left(3 \times 10^{8} \mathrm{CFU} / \mathrm{g}\right) \text {, } \\
\text { Bifidobacterium longum }\left(1 \times 10^{9} \mathrm{CFU} / \mathrm{g}\right) \\
\text { Streptococcus thermophilus }\left(3 \times 10^{8} \mathrm{CFU} / \mathrm{g}\right)\end{array}$ & 10 weeks & $\begin{array}{l}\text { Significant reduction in HAM-D } \\
\text { compared to the control group }\end{array}$ \\
\hline Lee et al. [42] & $\begin{array}{l}82 \text { (equal number } \\
\text { for control group) }\end{array}$ & Weissella cibaria $\left(1 \times 10^{10} \mathrm{CFU} / \mathrm{g}\right)$ & 2 months & $\begin{array}{l}\text { Major NK cell activity compared } \\
\text { to the control group }\end{array}$ \\
\hline Kouchaki et al. [41] & $\begin{array}{l}60 \text { (equal number } \\
\text { for control group) }\end{array}$ & $\begin{array}{l}\text { Lactobacillus acidophilus, Lactobacillus casei, } \\
\text { Bifidobacterium bifidum and Lactobacillus } \\
\text { fermentum }\left(2 \times 10^{9} \mathrm{CFU} / \mathrm{ml} \text { each) }\right.\end{array}$ & 3 months & $\begin{array}{l}\text { Significant reduction in BDI and } \\
\text { DASS compared to the control } \\
\text { group }\end{array}$ \\
\hline De Lorenzo et al. [37] & $\begin{array}{l}48 \text { (equal number } \\
\text { for control group) }\end{array}$ & $\begin{array}{l}3 \text { g POS containing Streptococcus thermophilus, } \\
\text { Bifidobacterium animalis subsp. lactis, } \\
\text { Bifidobacterium bifidum, Lactobacillus } \\
\text { delbrueckii, Lactobacillus lactis subsp. } \\
\text { lactis, Lactobacillus acidophilus, } \\
\text { Lactobacillus plantarum, Lactobacillus } \\
\text { reuteri }\left(1.5 \times 10^{9} \mathrm{CFU} / \mathrm{ml} \text { each) }\right.\end{array}$ & 3 weeks & $\begin{array}{l}\text { Significant reduction in } \\
\text { SCL90R-Dep compared to the } \\
\text { control group }\end{array}$ \\
\hline Marcial et al. [44] & $\begin{array}{l}42 \text { (equal number } \\
\text { for control group) }\end{array}$ & Lactobacillus johnsonii $\left(5 \times 10^{8} \mathrm{CFU} / \mathrm{g}\right)$ & 2 months & $\begin{array}{l}\text { Major NK cell activity and higher } \\
\text { percentage of CD8 cells } \\
\text { compared to the control group }\end{array}$ \\
\hline Pinto-Sanchez et al. [45] & $\begin{array}{l}44 \text { (equal number } \\
\text { for control group) }\end{array}$ & Bifidobacterium longum $\left(10^{10} \mathrm{CFU} / \mathrm{ml}\right)$ & 14 weeks & $\begin{array}{l}\text { HAM-D was significantly smaller } \\
\text { in } 6 \text { and } 10 \text { weeks compared to } \\
\text { the control group }\end{array}$ \\
\hline Akkasheh et al. [36] & $\begin{array}{l}40 \text { (equal number } \\
\text { for control group) }\end{array}$ & $\begin{array}{l}\text { Lactobacillus acidophilus, Lactobacillus casei, } \\
\text { Bifidobacterium bifidum }\left(2 \times 10^{9} \mathrm{CFU} / \mathrm{ml} \text { each }\right)\end{array}$ & 2 months & $\begin{array}{l}\text { Significant reduction in BDI by } \\
\text { probiotic compared to the } \\
\text { control group }\end{array}$ \\
\hline Kim et al. [40] & $\begin{array}{l}25 \text { (equal number } \\
\text { for control group) }\end{array}$ & Bacillus polyfermenticus $\left(3.1 \times 10^{8} \mathrm{CFU} / \mathrm{g}\right)$ & 18 weeks & $\begin{array}{l}\text { Major concentration of IgG, } \\
\text { higher percentage of CD4 cells, } \\
\text { CD8 cells and CD56 cells } \\
\text { compared to the control group }\end{array}$ \\
\hline
\end{tabular}

POS, psychobiotics oral suspension; HAM-D, Hamilton rating scale for depression; MADRS, Montgomery-Åsberg depression rating scale; BDI, Beck depression inventory; NK, natural killer; DASS, Depression, anxiety and stress scale; SCL90R-Dep, Symptom checklist 90-depression; IgG, immunoglobulin G. 
are proteins that attach themselves to pathogens. This signals immune cells to destroy the pathogen. Some T and B cells change into memory cells to combat reinfection by the same pathogen [24,31].

Different Lactobacillus strains are consumed. Lactobacillus can be used in immunotherapeutic applications such as a “oral vaccination - therapy” for T cell tolerance induction against autoimmune disease [32]. Oral administration of Lactobacillus reuteriand Lactobacillus brevis induced expression of the pro-inflammatory cytokines [32]. Cytokines are small proteins $(\sim 5-20 \mathrm{kDa})$ important in cell signaling. Cytokines modulate the balance between humoral and cell-based immune responses and are important in health and disease, specifically in host immune responses to infection and inflammation [32]. Lactobacillus strain selection provides a strategy to influence cytokine expression and generate an immune response, improving the host immune system [32].

Lactobacillus rhamnosus reduced the cell multiplication of Escherichia coli O157: H7 in infected mice experimentally, stimulating the increase of the macrophage activity and IgA antibody [33]. Perdigón et al. [34] demonstrated that Lactobacillus casei and Lactobacillus plantarum interacted with the $M$ cells of the Peyer plaques, stimulating a specific secretory immunity.

Shu et al. [35] reported that piglets treated with Lactobacillus lactis HN109 showed decreased diarrhea associated with Rotavirus, increasing antibodies against specific pathogens in the gastrointestinal tract. Treatment also increased the concentration of blood neutrophils and the proliferative response of $\mathrm{T}$ lymphocytes.

Table 1 shows the characteristics of trials on the probiotics dosage effect on host body functionality. Overall, the effect of probiotics microorganisms on satisfactory response to the host showed a wide variance across the included studies. An important consideration of this review is the vast range of microbial strains used in clinical trials. Of the included studies in this review, microbial strains were the same in different trials, providing different benefits. It follows that a single strain or various microbial strains, lumped together as "Probiotic consumption therapy” can be applied for benefits to the host [36-45].

\section{DISCUSSION}

Several scientific studies have shown the importance of the gut-brain-microbiome axis [2-4,23,24]. Gut-brain-microbiome axis has proven to be fundamental for the host well-being. For a while, the brain was searched exclusively for the psychiatric illnesses origin $[2,31]$. However, others research sources are in the literature. There is evidence in the literature about the ability gut microbiome ability in modulate the immune system through the gut-brain axis $[3,4,24,46]$.

Intestinal dysbiosis affects the host's immune system. The influence of the microbiome on the gut-brain axis is justified by the growing study of psychobiotics in the most diverse areas, such as health sciences, microbiology, neurology, biotechnology and food sciences. Gut-brain axis must be considered as a "virtual organ" of the host, given its importance for its mental and physical balance. Combating intestinal dysbiosis in an individual over time becomes essential in the prevention of pathological conditions. The development of new therapies, such as "psychobiotic therapy", is extremely important. The literature shows that the intestinal dysbiosis interferes on gut-brain axis balance and consequent host immune decline $[3,4,24,46]$.

Through simple strategies, such as probiotic use and a healthy diet with cereals, vegetables and fruits (e.g., orange juice as a prebiotic in the balance of the intestinal microbiota and glycemic/lipid index [16], each person can improve the intestinal microbiome and keep the gut-brain system healthy. Psychobiotic therapy has proven antidepressant/anxiolytic properties [7,8,14]. Thus, the use of "Psychobiotic Therapy" in the daily diet is opportune and gains more and more prominence. Psychobiotic therapy may ultimately be used to reinforce host immune balance against pathogens, for example: virus $[4,35]$, bacteria and fungus $[4,24,33]$.

Correlating with the current time, the benefits of using psychobiotic microorganisms can be enjoyed by the general population. For example, the world today suffers from a pandemic, COVID-19. COVID-19 is a highly infectious disease caused by the severe acute respiratory syndrome coronavirus-2 (SARS-CoV-2), which is responsible for the development of serious and even fatal respiratory disorders [47]. In addition to physical disorders, COVID-19 outbreak can also harm the mental health of professionals and the general population, causing anxiety, stress, panic and depression, may result in immune imbalance [48-51]. In view of this, there is a clear need for 
the urgent methods that aim to the balance of the population's mental health. Thus, the utilization of psychotropic remedy to control problems related to emotional health during this pandemic is almost inevitable. The use these remedy are often associated with endocrine and metabolic side effects, which involve changes in the composition of the gut microbiota, may result in disorders such weight loss, weight gain, metabolic syndrome, diabetes, hyperparathyroidism, hypothyroidism, hypertension and sexual dysfunction [46]. Thus, the adoption of less aggressive "therapy" to the host body need to be considered, such as "Psychobiotic Therapy" [52-56]. The main advantages of using psychobiotic therapy in maintaining mental health during the pandemic such as COVID-19 is that, because they are microorganisms that belong to microbial genera naturally found in the intestinal tract (Fig. 1), they may present a lower risk of body rejection reactions causing allergies or other disorders. In light of the above, could psychobiotic (probiotics) microorganisms be a alternative for maintaining mental health in the face of a fragile population. Certainly, future clinical approaches are needed to ascertain their effectiveness in improving menthal disorders resulting from the evolution of COVID-19 outbreak. However, some potential strategies include the use of probiotic foods and natural, which have reports in the scientific literature of their numerous probiotic and nutritional benefits, such as "kefir" and "kombucha" [27-29,30,57-60].

\section{CONCLUSIONS}

An increasing number of reports have emerged and provided evidence for the effects of psychobiotics (probiotics microorganisms) in the balancing action of the gut-brain axis $[52,53,56,60]$. Some of single or multiple microbial strains can beneficially affect the central nervous system functions mediated by the gut-brain axis, improving the host immune system, including mood, anxiety, depression and stress. This results in a promising host defense against bacterial, fungal and viral pathogens. Thus, psychobiotic therapy can be a promising strategy to improve and/or maintain the quality of life of people who are healthy or who suffer from anxiety/stress disorders, intestinal dysbiosis and even immunosuppressed people.

This is such a hot theme it can surely only be a matter of time for psychobiotic therapy offers an "alternative treat- ment”, but scientific, for people diagnosed with a variety of mental/immunological disorders. Instead of targeting the mind (brain), we could go for the gut. "This new way of looking at mental health linked to gut health is literally looking at health upside down".

\section{Funding}

None.

\section{Acknowledgments}

The author thanks the Federal University of Bahia UFBA, Postgraduate Program in Food Science - (PGALi), the National Council for Scientific and Technological Development - (CNPq) and Coordination for the Improvement of Higher Education Personnel - (CAPES) for their support in various scientific research.

\section{Conflicts of Interest}

No potential conflict of interest relevant to this article was reported.

\section{REFERENCES}

1. Eberl G. Immunity by equilibrium. Nat Rev Immunol 2016; 16:524-532.

2. Dinan TG, Stanton C, Cryan JF. Psychobiotics: a nove/ class of psychotropic. Biol Psychiatry 2013;74:720-726.

3. Magalhães-Guedes KT. The dialogue between the intestine-brain axis: what is the role of probiotics? Asian Food SCi J 2020;14:23-27.

4. Ross SM. Microbiota in neuropsychiatry, part 3: psychobiotics as modulators of mood disorders. Holist Nurs Pract 2017; 31:270-273.

5. Petra Al, Panagiotidou S, Hatziagelaki E, Stewart JM, Conti P, Theoharides TC. Gut-microbiota-brain axis and its effect on neuropsychiatric disorders with suspected immune dysregulation. Clin Ther 2015;37:984-995.

6. Wei X, Zhao J, Jia X, Zhao X, Li H, Lin W, et al. Abnormal gut microbiota metabolism specific for liver cirrhosis. Front Microbiol 2018;9:3051.

7. O'Mahony SM, Clarke G, Borre YE, Dinan TG, Cryan JF. Serotonin, tryptophan metabolism and the brain-gut-microbiome axis. Behav Brain Res 2015;277:32-48.

8. Roshchina VV. New trends and perspectives in the evolution of neurotransmitters in microbial, plant, and animal cells. Adv Exp Med Biol 2016;874:25-77.

9. Sarkar A, Lehto SM, Harty S, Dinan TG, Cryan JF, Burnet PWJ. Psychobiotics and the manipulation of bacteria-gut-brain signals. Trends Neurosci 2016;39:763-781.

10. Tian P, O'Riordan KJ, Lee YK, Wang G, Zhao J, Zhang H, et al. Towards a psychobiotic therapy for depression: Bifidobacterium 
breve CCFM1025 reverses chronic stress-induced depressive symptoms and gut microbial abnormalities in mice. Neurobiol Stress 2020;12:100216.

11. Martinowich K, Lu B. Interaction between BDNF and serotonin: role in mood disorders. Neuropsychopharmacology 2008;33:73-83.

12. Cheng LH, Liu YW, Wu CC, Wang S, Tsai YC. Psychobiotics in mental health, neurodegenerative and neurodevelopmental disorders. J Food Drug Anal 2019;27:632-648.

13. Sudo N, Chida Y, Aiba Y, Sonoda J, Oyama N, Yu XN, et al. Postnatal microbial colonization programs the hypothalamicpituitary-adrenal system for stress response in mice. J Physiol 2004;558(Pt 1):263-275.

14. Silverman MN, Sternberg EM. Glucocorticoid regulation of inflammation and its functional correlates: from HPA axis to g/ucocorticoid receptor dysfunction. Ann N Y Acad Sci 2012; 1261:55-63.

15. Chang JP, Su KP. Nutritional neuroscience as mainstream of psychiatry: the evidence- based treatment guidelines for using omega-3 fatty acids as a new treatment for psychiatric disorders in children and adolescents. Clin Psychopharmacol Neurosci 2020;18:469-483.

16. Fidélix M, Milenkovic D, Sivieri K, Cesar T. Microbiota modulation and effects on metabolic biomarkers by orange juice: a controlled clinical trial. Food Funct 2020;11:1599-1610.

17. Gibson GR, Probert HM, Loo JV, Rastall RA, Roberfroid MB. Dietary modulation of the human colonic microbiota: updating the concept of prebiotics. Nutr Res Rev 2004;17:259-275.

18. Betiku OC, Yeoman CJ, Gaylord TG, Duff GC, Hamerly T, Bothner B, et al. Differences in amino acid catabolism by gut microbes with/without prebiotics inclusion in GDDY-based diet affect feed utilization in rainbow trout. Aquaculture 2018:490:108-119.

19. Sun MF, Shen YQ. Dysbiosis of gut microbiota and microbial metabolites in Parkinson's disease. Ageing Res Rev 2018;45: 53-61.

20. Vaiserman AM, Koliada AK, Marotta F. Gut microbiota: a player in aging and a target for anti-aging intervention. Ageing Res Rev 2017;35:36-45.

21. Vanuytsel T, van Wanrooy S, Vanheel H, Vanormelingen C, Verschueren S, Houben E, et al. Psychological stress and corticotropin-releasing hormone increase intestinal permeability in humans by a mast cell-dependent mechanism. Gut 2014; 63:1293-1299.

22. Huo R, Zeng B, Zeng L, Cheng K, Li B, Luo Y, et al. Microbiota modulate anxiety-like behavior and endocrine abnormalities in hypothalamic-pituitary-adrenal axis. Front Cell Infect Microbiol 2017;7:489.

23. Bercik P, Collins SM, Verdu EF. Microbes and the gut-brain axis. Neurogastroenterol Motil 2012;24:405-413.

24. Wang Y, Jiang Y, Deng Y, Yi C, Wang Y, Ding M, et al. Probiotic supplements: hope or hype? Front Microbiol 2020; 11:160.
25. Mousavi SN, Saboori S, Asbaghi O. Effect of daily probiotic yogurt consumption on inflammation: a systematic review and meta-analysis of randomized Controlled Clinical trials. Obes Med 2020;18:100221.

26. Santos MS, Estevinho LM, Carvalho CAL, Morais JS, Conceição ALS, Paula VB, et al. Probiotic yogurt with Brazilian red propolis: physicochemical and bioactive properties, stability, and shelf life. J Food Sci 2019;84:3429-3436.

27. Magalhães KT, Dragone G, de Melo Pereira GV, Oliveira JM, Domingues L, Teixeira JA, et al. Comparative study of the biochemical changes and volatile compound formations during the production of novel whey-based kefir beverages and traditional milk kefir. Food Chem 2011;126:249-253.

28. Puerari C, Magalhães KT, Schwan RF. New cocoa pulp-based kefir beverages: Microbiological, chemical composition and sensory analysis. Food Res Int 2012;48:634-640.

29. Andrade AB, Souza CCA, Grimaut DA, Porto EA, Silva GS, Silva JSJ, et al. Kombucha-based cocoa honey beverage. World App/ Sci J 2020;38:58-64.

30. Magalhães-Guedes KT, da Anunciação TA, Schwan RF. Kombucha and kefir are foods of the 21st century: a opinion. J Biotech Biores 2019;2:01-02.

31. Cross ML. Microbes versus microbes: immune signals generated by probiotic lactobacilli and their role in protection against microbial pathogens. FEMS Immunol Med Microbiol 2002;34:245-253.

32. Maassen CB, van Holten-Neelen C, Balk F, den BakGlashouwer MJ, Leer RJ, Laman JD, et al. Strain-dependent induction of cytokine profiles in the gut by orally administered Lactobacillus strains. Vaccine 2000;18:2613-2623.

33. Shu Q, Gill HS. Immune protection mediated by the probiotic Lactobacillus rhamnosus HNOO1 (DR20) against Escherichia coli O157:H7 infection in mice. FEMS Immunol Med Microbiol 2002;34:59-64.

34. Perdigón G, Vintiñi E, Alvarez S, Medina M, Medici M. Study of the possible mechanisms involved in the mucosal immune system activation by lactic acid bacteria. J Dairy Sci 1999; 82:1108-1114.

35. Shu Q, Qu F, Gill HS. Probiotic treatment using Bifidobacterium lactis HNO19 reduces weanling diarrhea associated with rotavirus and Escherichia coli infection in a piglet model. $J$ Pediatr Gastroenterol Nutr 2001;33:171-177.

36. Akkasheh G, Kashani-Poor Z, Tajabadi-Ebrahimi M, Jafari P, Akbari $\mathrm{H}$, Taghizadeh $\mathrm{M}$, et al. Clinical and metabolic response to probiotic administration in patients with major depressive disorder: a randomized, double-blind, placebo-controlled trial. Nutrition 2016;32:315-320.

37. De Lorenzo A, Costacurta M, Merra G, Gualtieri P, Cioccoloni G, Marchetti M, et al. Can psychobiotics intake modulate psychological profile and body composition of women affected by normal weight obese syndrome and obesity? A double blind randomized clinical trial. I Trans/ Med 2017;15:135.

38. Ghorbani Z, Nazari S, Etesam F, Nourimajd S, Ahmadpanah 
$\mathrm{M}$, Jahromi SR. The effect of synbiotic as an adjuvant therapy to fluoxetine in moderate depression: a randomized multicenter trial. Arch Neurosci 2018;5:e60507.

39. Kazemi A, Noorbala AA, Azam K, Eskandari MH, Djafarian K. Effect of probiotic and prebiotic vs placebo on psychological outcomes in patients with major depressive disorder: a randomized clinical trial. Clin Nutr 2019;38:522-528.

40. Kim HS, Park H, Cho IY, Paik HD, Park E. Dietary supplementation of probiotic Bacillus polyfermenticus, Bispan strain, modulates natural killer cell and T cell subset populations and immunoglobulin G levels in human subjects. J Med Food 2006;9:321-327.

41. Kouchaki E, Tamtaji OR, Salami M, Bahmani F, Daneshvar Kakhaki R, Akbari E, et al. Clinical and metabolic response to probiotic supplementation in patients with multiple sclerosis: a randomized, double-blind, placebo-controlled trial. Clin Nutr 2017;36:1245-1249.

42. Lee YJ, Lee A, Yoo HJ, Kim M, Noh GM, Lee JH. Supplementation with the probiotic strain Weissella cibaria JW15 enhances natural killer cell activity in nondiabetic subjects. J Funct Foods 2018;48:153-158.

43. Majeed M, Nagabhushanam K, Arumugam S, Majeed S, Ali F. Bacillus coagulans MTCC 5856 for the management of major depression with irritable bowel syndrome: a randomised, double-blind, placebo controlled, multi-centre, pilot clinical study. Food Nutr Res 2018;62:1218.

44. Marcial GE, Ford AL, Haller MJ, Gezan SA, Harrison NA, Cai D, et al. Lactobacillus johnsonii N6.2 modulates the host immune responses: a double-blind, randomized trial in healthy adults. Front Immunol 2017;8:655.

45. Pinto-Sanchez MI, Hall GB, Ghajar K, Nardelli A, Bolino C, Lau JT, et al. Probiotic Bifidobacterium longum NCC3001 reduces depression scores and alters brain activity: a pilot study in patients with irritable bowel syndrome. Gastroenterology 2017;153:448-459.e8.

46. Cussotto S, Strain CR, Fouhy F, Strain RG, Peterson VL, Clarke $\mathrm{G}$, et al. Differential effects of psychotropic drugs on microbiome composition and gastrointestinal function. Psychopharmacology (Berl) 2019;236:1671-1685.

47. Zhang J, Wang X, Jia X, Li J, Hu K, Chen G, et al. Risk factors for disease severity, unimprovement, and mortality in COVID-19 patients in Wuhan, China. Clin Microbiol Infect 2020;26:767772.

48. Rajkumar RP. COVID-19 and mental health: a review of the existing literature. Asian J Psychiatr 2020;52:102066.
49. Wei P, Keller C, Li L. Neuropeptides in gut-brain axis and their influence on host immunity and stress. Comput Struct Biotechnol J 2020;18:843-851.

50. Evrensel A, Ceylan ME. The gut-brain axis: the missing link in depression. Clin Psychopharmacol Neurosci 2015;13:239-244.

51. Do J, Woo J. From gut to brain: alteration in inflammation markers in the brain of dextran sodium sulfate-induced colitis model mice. Clin Psychopharmacol Neurosci 2018;16:422433.

52. Heidarzadeh-Rad N, Gökmen-Özel H, Kazemi A, Almasi N, Djafarian K. Effects of a psychobiotic supplement on serum brain-derived neurotrophic factor levels in depressive patients: a post hoc analysis of a randomized clinical trial. J Neurogastroenterol Motil 2020;26:486-495.

53. Wu SI, Wu CC, Tsai PJ, Cheng LH, Hsu CC, Shan IK, et al. Psychobiotic supplementation of PS128TM improves stress, anxiety, and insomnia in highly stressed information technology specialists: a pilot study. Front Nutr 2021;8:614105.

54. Tian P, Bastiaanssen TFS, Song L, Jiang B, Zhang X, Zhao J, et al. Unraveling the microbial mechanisms underlying the psychobiotic potential of a Bifidobacterium breve strain. Mol Nutr Food Res 2021;65:e2000704.

55. Sun $\mathrm{H}, \mathrm{Ma} \mathrm{Y}, \mathrm{An} \mathrm{S}$, Wang Z. Altered gene expression signatures by calcitonin gene-related peptide promoted mast cell activity in the colon of stress-induced visceral hyperalgesia mice. Neurogastroenterol Motil 2021;33:e14073.

56. Barouei J, Moussavi M, Hodgson DM. Effect of maternal probiotic intervention on HPA axis, immunity and gut microbiota in a rat model of irritable bowel syndrome. PLoS One 2012;7: e46051.

57. Vitas JS, Cvetanović AD, Mašković PZ., Švarc-Gajić JV, Malbaša RV. Chemical composition and biological activity of novel types of kombucha beverages with yarrow. J Funct Foods 2018;44:95-102.

58. Magalhães-Guedes KT, Barreto IT, Tavares PPLG, Bezerra PQM, Silva MR, Nunes IL, et al. Effect of kefir biomass on nutritional, microbiological, and sensory properties of mangobased popsicles. Int Food Res J 2020;27:536-545.

59. de Souza BL, Magalhães-Guedes KT, Lemos PVF, Maciel LF, Dias DR, Druzian JI, et al. Development of arrowroot flour fermented by kefir grains. J Food Sci 2020;85:3722-3730.

60. Davras F, Guzel-Seydim ZB, Tas TK. Immunological effects of Kefir produced from Kefir grains versus starter cultures when fed to mice. Funct Foods Health Dis 2018;8:412-423. 